\title{
Inversion of high-rate (1 sps) GPS data for rupture process of the 11 March 2011 Tohoku earthquake $\left(M_{w}\right.$ 9.1)
}

\author{
H. Yue ${ }^{1}$ and T. Lay ${ }^{1}$ \\ Received 27 June 2011; revised 5 August 2011; accepted 8 August 2011; published 8 September 2011.
}

[1] The space-time fault displacement history of the 11 March 2011 Tohoku $\left(\mathrm{M}_{\mathrm{w}}\right.$ 9.1) megathrust earthquake is obtained by least-squares inversion of high-rate (1 sample per second) GPS ground motions recorded in Japan. Complete near-source time-varying and static ground motions for periods $\geq 25 \mathrm{~s}$ are fit in the inversion using a normal mode formalism to compute the Green functions. The basic rupture pattern is stable for various choices of model parameters and solution smoothing, and excellent fits to the complete seismo-geodetic ground motions are obtained. The preferred solution has concentrations of slip near the trench and hypocenter, with sub-fault source time function durations of $\sim 30-70$ s and maximum slip of $\sim 60 \mathrm{~m}$. Down-dip slip spreads over a wider area with smaller maximum slip $(<\sim 10-15 \mathrm{~m})$. Inversion of the highrate GPS data exploits both the timing and total displacement information in the ground motions, yielding stable estimates of the seismic moment $\left(\sim 4.8 \times 10^{22} \mathrm{Nm}\right.$; $\mathrm{M}_{\mathrm{w}}=9.1$ ) and slip distribution. Citation: Yue, H., and T. Lay (2011), Inversion of high-rate (1 sps) GPS data for rupture process of the 11 March 2011 Tohoku earthquake $\left(\mathrm{M}_{\mathrm{w}} 9.1\right)$, Geophys. Res. Lett., 38, L00G09, doi:10.1029/2011GL048700.

\section{Introduction}

[2] Seismic, geodetic and tsunami observations are now commonly used to estimate finite-fault slip distribution models for large earthquakes either by separate or joint inversion procedures [e.g., Ji et al., 2004; Delouis et al., 2010; Konca et al., 2010]. There are advantages and limitations associated with each type of data, and development of unified models that exploit the collective advantages is a long-term goal. To date, most joint inversions of seismic and geodetic observations involved modeling of seismic waves and static ground motion displacements using separate wave propagation and static motion algorithms, and there is uncertainty in weighting of the distinct information from each data type. With the advent of high-rate GPS recordings, the distinctions between seismic and geodetic observations and modeling have become blurred, as recordings close to an event contain the progression of all seismic arrivals accompanied by near-field terms that evolve into the static offsets. By computing complete ground motion Green functions accounting for all of these contributions, the high-rate GPS time series can essentially be treated like seismograms including any detectable static offsets. This has been the case for analysis of recordings from twice-integrated strong

\footnotetext{
${ }^{1}$ Department of Earth and Planetary Sciences, University of California, Santa Cruz, California, USA.

Copyright 2011 by the American Geophysical Union. 0094-8276/11/2011GL048700
}

motion accelerometers for decades, but thus far there have been relatively few inversions of time-varying high-rate GPS observations for finite-faulting models [e.g., Miyazaki et al., 2004; Ammon et al., 2011].

[3] We develop an inversion algorithm that constrains the rupture process for the great 2011 Tohoku event using threecomponent 1-sps high-rate GPS ground position solutions. Simultaneous inversion of the time-varying GPS recordings of seismic and static motions provides a well-resolved rupture model for the earthquake, and the formalism can readily be extended to incorporate teleseismic observations for all seismic arrivals.

\section{The 2011 Tohoku Earthquake Observations}

[4] The 11 March 2011 Tohoku earthquake ruptured the entire width of the megathrust offshore of northeastern Japan, producing many geophysical observations that have been rapidly analyzed to constrain the rupture process. Direct measures of bathymetric motions of the seafloor resolve seaward displacements of the upper plate by $\sim 24 \mathrm{~m}$ above the hypocenter [Sato et al., 2011] and $\sim 50 \mathrm{~m}$ near the trench (http://www.jamstec.go.jp/j/about/press_release/20110428/). Finite-fault rupture models inverted from teleseismic and low-pass filtered strong-motion data indicate that the largest fault displacements are located up-dip of the hypocenter with slip of 40-60 m extending to the trench [e.g., Ammon et al., 2011; Hayes, 2011; Ide et al., 2011; Lay et al., 2011b; Simons et al., 2011; Yoshida et al., 2011]. Modeling and inversions of tsunami data support large near-trench slip [e.g., Lay et al., 2011a; Fujii et al., 2011; Maeda et al., 2011] Geodetic inversions of static GPS coseismic offsets tend to concentrate large slip in the central region of the rupture zone, near the hypocenter [e.g., Iinuma et al., 2011; Ozawa et al., 2011; Simons et al., 2011], although it seems likely they have limited resolution of more seaward slip. On the other hand, back-projections of teleseismic short-period seismic wave energy indicate source locations primarily in the downdip portion of the megathrust below the coast, not in the up-dip regions of large slip [Koper et al., 2011; Simons et al., 2011; Wang and Mori, 2011].

[5] Over 400 high-rate three-component GPS estimated ground motion time series were made available courtesy of GPS-Solutions. The ground motion records were obtained from $1 \mathrm{~Hz}$ GEONET data, provided by the Geospatial Information Authority of Japan (GSI) via Nippon GPS Data Services Company (NGDS), post-processed in real-time mode with real-time orbits and clock corrections from the VERIPOS/APEX global service using the real-time network (RTNet) software of GPS-Solutions. Estimated detection of co-seismic surface displacements of $1 \mathrm{~cm}$ horizontal and $2.5 \mathrm{~cm}$ vertical is achieved, and favorable comparisons with 


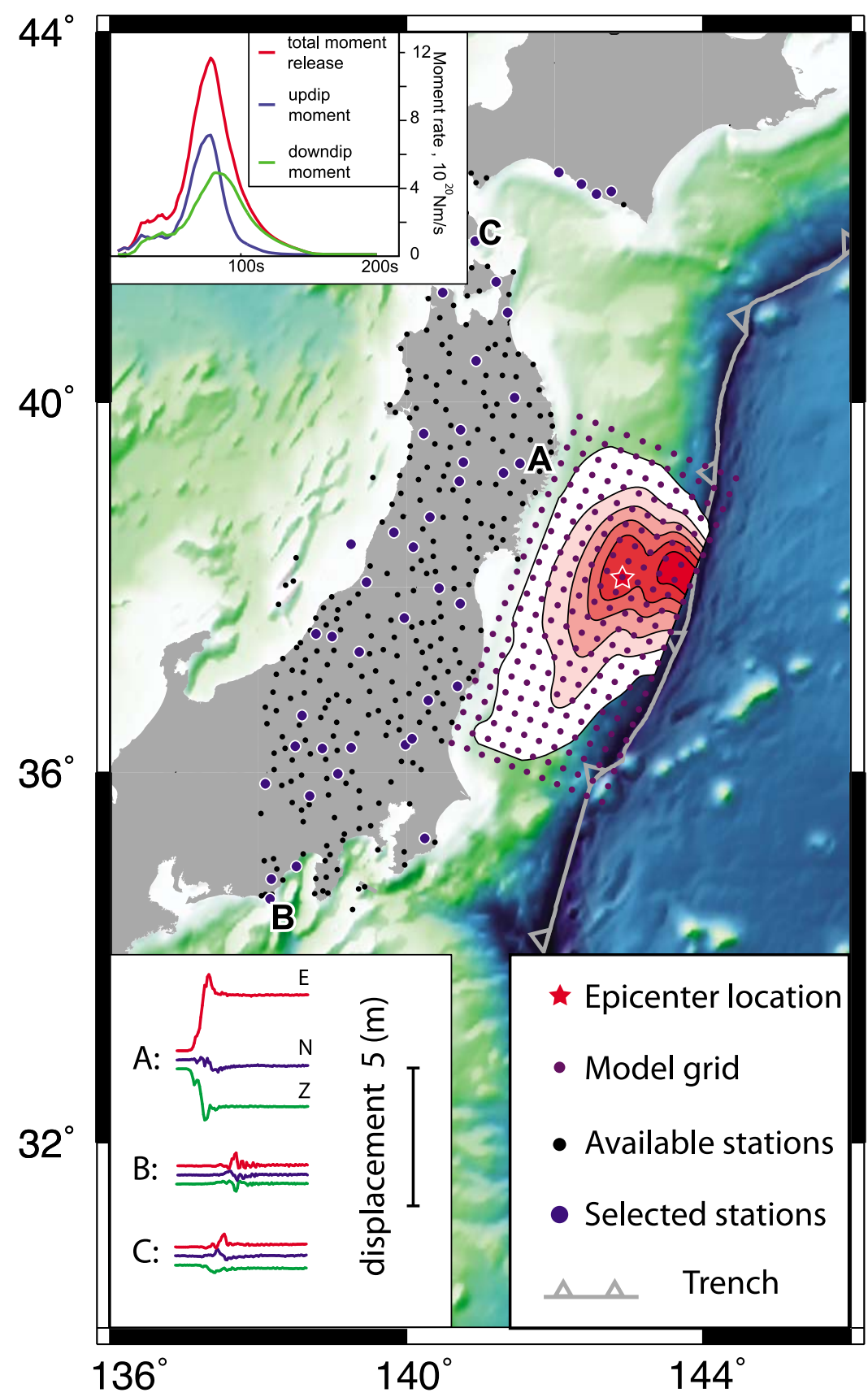

Figure 1. Station distribution and model grid positions (purple filled circles). Available and selected stations are marked as black and larger blue filled circles, respectively. The red star marks the epicenter. The preferred slip distribution is shown on the grid (slip contours are at $1 \mathrm{~m}, 10 \mathrm{~m}, 20 \mathrm{~m}, 30 \mathrm{~m}, 40 \mathrm{~m}$ and $50 \mathrm{~m}$ ). The trench is marked with a gray barbed line. Example three-component high-rate GPS ground motions of three stations (A, B and C on the map), are plotted on the bottom. Moment rate functions for the whole fault plane, and up-dip and down-dip of hypocenter portions of the fault are shown on the top left.

Bernese processing are documented on the GPS-Solutions website. Estimated standard deviations of the horizontal component signals we use are $\sim 0.02 \mathrm{~m}$, while for vertical components the standard deviations are $\sim 0.04 \mathrm{~m}$. For the characteristic horizontal peak displacements of several meters, these random errors are a few percent, which is small relative to uncertainties in model parameters for our inversions. We did not reprocess the raw GPS data, but compared the ground motion estimates for nearby stations and with independently-processed ARIA data (with $30 \mathrm{~s}$ sampling) to ensure reliability.

[6] We chose variously distributed subsets of 43 high signal-to-noise ratio stations to invert for the slip-distribution, selecting stations to provide good location constraints parallel to the Honshu coast (Figure 1). The results here are for one subset; inversions with different groups of stations were used to evaluate stability of the solutions and to ensure that any errors due to multipathing do not contaminate the 

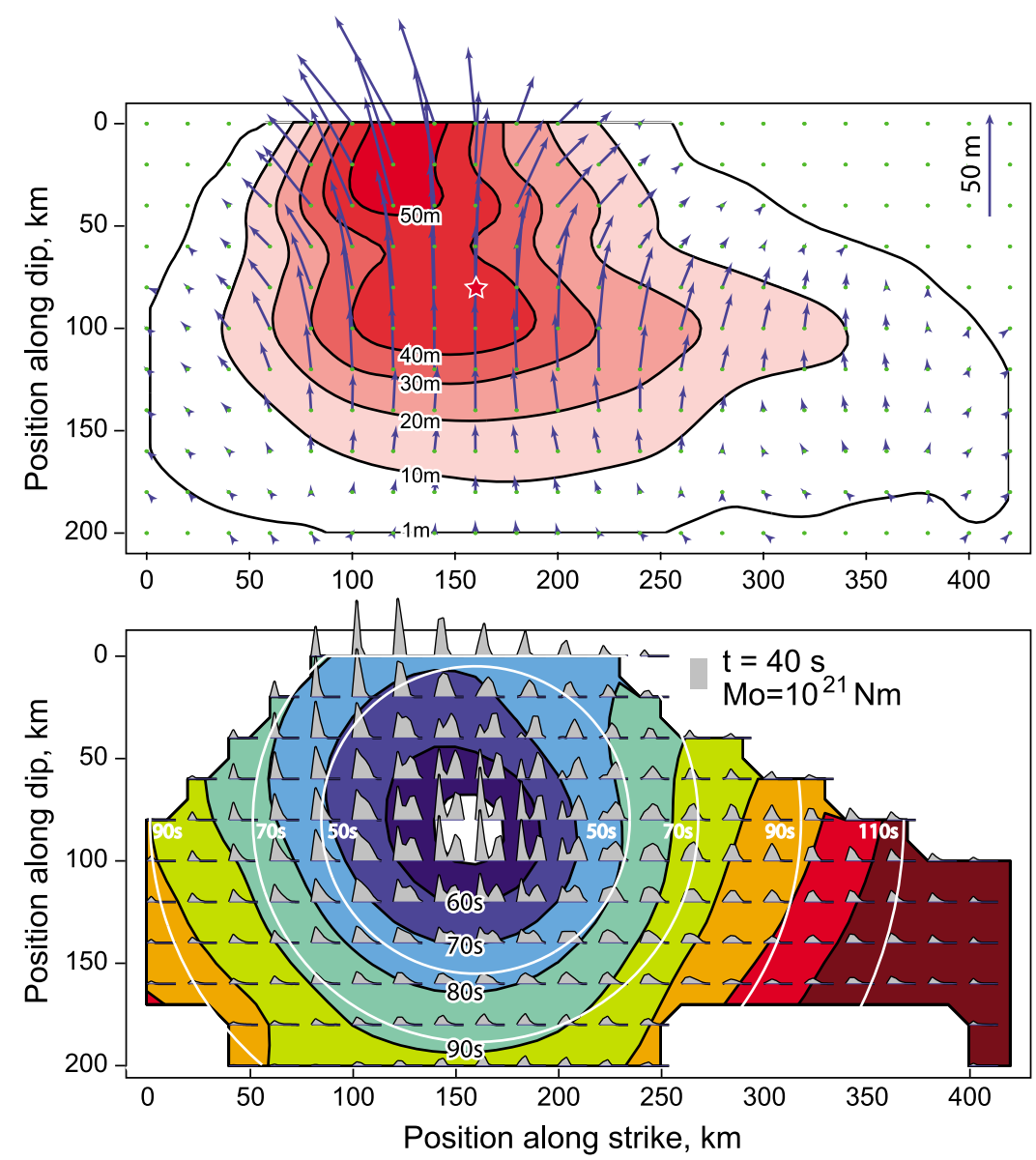

Figure 2. (top) Preferred model slip distribution, with the maximum slip value of $\sim 60 \mathrm{~m}$ at the top center grid and total seismic moment of $\sim 4.8 \times 10^{22} \mathrm{Nm}$. (bottom) The source time functions for all sub-faults are shown as gray polygons, with the sub-fault source function centroid value time shown as colored background with black contours labeled by the black numbers. A rectangle with the area of seismic moment of $10^{21} \mathrm{Nm}$ and time duration of $40 \mathrm{~s}$ is plotted as a reference for the sub-fault source time functions. Rupture expansion time counters are marked as white concentric circles labeled with white numbers.

solutions. These hr-GPS signals are free of the bandwidth and clipping limitations of regional broadband seismometers for resolving the dynamic displacements and do not require unstable double integration as is the case for strong motion recordings in order to resolve the co-seismic static displacements. They are limited to resolving signal periods longer than $\sim 10 \mathrm{~s}$ and have noise attributes that depend on the signal processing. The timing information and wide range of apparent velocities from $\mathrm{P}$ wave to little-dispersed Rayleigh wave arrivals in the regional high-rate GPS recordings provides good spatial resolution of the faulting process, while the explicit inclusion of static deformations bounds the total seismic moment and slip distribution.

\section{Model Parameters and Inversion}

[7] The fault model (Figure 1) has eleven $20 \times 20 \mathrm{~km}^{2}$ sub-faults along dip and twenty-two along a strike of $202^{\circ}$. The dip of the model rupture plane varies over 2 segments; the dip is $10^{\circ}$ shallower than $27 \mathrm{~km}$ beneath sea level and $22^{\circ}$ below $27 \mathrm{~km}$, approximated from the seismic reflection model of Miura et al. [2005]. Inversions for various constant dip values and 3-segment models with a shallow segment dipping only $5^{\circ}$ were performed, with generally consistent results to the model presented here. The source time function of each subfault is parameterized by 6 triangles with $10 \mathrm{~s}$ half-time durations shifted by $10 \mathrm{~s}$ each, giving total subfault durations of up to $70 \mathrm{~s}$. The rake is allowed to vary between sub-events for each sub-fault. The hypocenter location is at the 9th grid point along strike (counting from northeast) and 5th grid along dip (counting from up-dip position near the trench). We use the relocated epicenter from Zhao et al. [2011] $\left(38.11^{\circ} \mathrm{E}, 142.92^{\circ} \mathrm{N}\right)$, an initial depth of $20 \mathrm{~km}$ beneath sea level, and an origin time of 14:46: 18.14 UTC. Ground motion time windows up to $600 \mathrm{~s}$ long starting at the origin time were inverted, eliminating any need to pick first arrival times for the very emergent signal onsets. The preferred initial rupture expansion velocity is $1.5 \mathrm{~km} / \mathrm{s}$ out to a distance of $100 \mathrm{~km}$ from the hypocenter, and then increases to $2.5 \mathrm{~km} / \mathrm{s}$, based on back-projection imaging [Koper et al., 2011] and finite-fault modeling of teleseismic signals [Ammon et al., 2011; Lay et al., 2011b].

[8] Inversion of the complete ground motion recordings requires computation of Green functions including all dynamic and static terms. Normal mode summation of all modes for PREM [Dziewonski and Anderson, 1981] up to $80 \mathrm{mHz}$ was used to generate Green functions, using a mode set provided by L. Rivera, accounting for all seismic and 


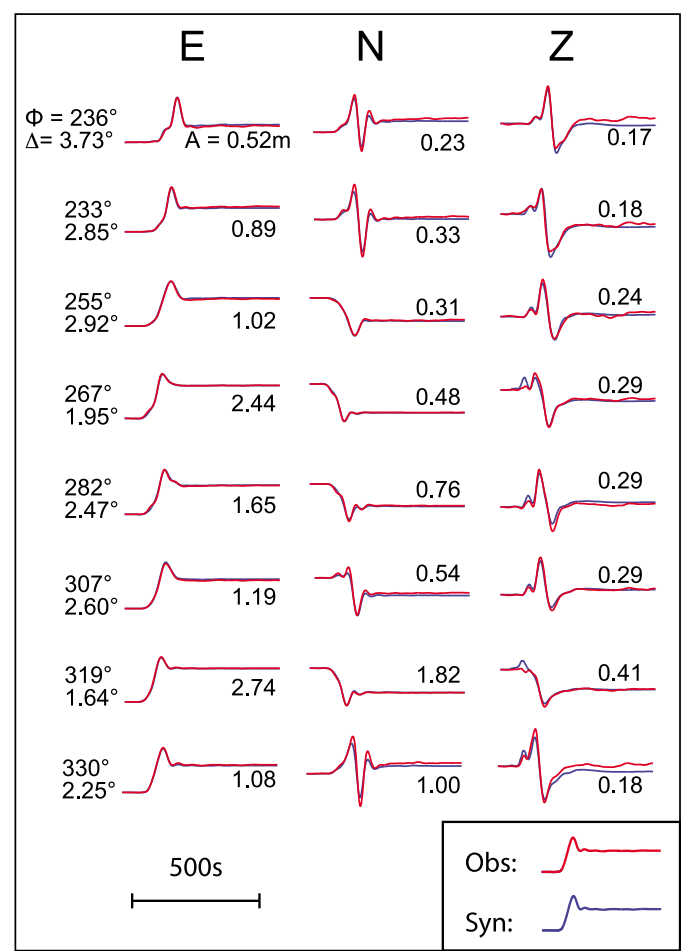

Figure 3. Three-component ( $\mathrm{E}$ - east; $\mathrm{N}$ - north; $\mathrm{Z}$ - vertical) high-rate GPS ground motion observations (red curves) and preferred model predictions (blue curves) for 8 of the 43 stations used in the inversion (all station data and predictions are shown in Figure S1). Station, azimuth $(\phi)$ and epicenter distance $(\Delta)$, and peak absolute displacement amplitude, $\mathrm{A}$, in $\mathrm{m}$ are shown for each waveform.

static ground motions with intrinsically balanced weighting of information. To reduce the computational effort, we obtain the Green functions for each sub-fault-station pair using a pre-calculated database with $10 \mathrm{~km}$ epicentral spacing and $1 \mathrm{~km}$ source depth spacing. We use the Green's function for the nearest node from the database for each station, incurring minor errors $(<5 \mathrm{~km})$ in propagation distance, insignificant for the $80 \mathrm{mHz}$ limit of the signal spectrum. We apply a low-pass filter to the data and the Green functions to ensure common spectral content and to eliminate mode truncation ringing and noise in the processed data. PREM has a simple 1D structure so the lowpass filtering also suppresses short-period signals that are poorly predicted by the model. On the other hand, filtering reduces time resolution and some seismic wave features, so the low-pass filter is selected carefully to balance the tradeoff between the time resolution and the model effectiveness. We present results for a low-pass corner at $25 \mathrm{~s}$, but very similar results are found using corners of $20 \mathrm{~s}$ to $40 \mathrm{~s}$. Green functions for rakes of $45^{\circ}$ and $135^{\circ}$ for each sub-fault are used in a non-negative least square inversion [Lawson and Hanson, 1995], constraining each sub-fault rake to be within that range.

[9] We add a smoothing weight matrix to the Green's function matrix to constrain the corresponding triangle subevents of adjacent sub-faults. No smoothing in time was applied to the different sub-events for the same sub-fault. The smoothing factor, $\beta_{\mathrm{i}}$, between adjacent sub-faults for a given model parameter $i$, is calculated by $\beta_{\mathrm{i}}=\beta_{\mathrm{o}}\left(\Sigma_{\mathrm{j}} \boldsymbol{G}_{i j}^{2}\right)^{0.5}$ / $\left(d x^{2}+d y^{2}\right), \beta_{\mathrm{o}}$ is an adjustable smoothing weight, $\boldsymbol{G}_{i j}$ is the time-integrated power of each Green function associated with parameter $i$ for station $j, d x$ and $d y$ are the segment dimensions for each sub-fault. The physical significance of this algorithm is that sub-faults with higher Green function amplitudes (usually closer to stations) are smoothed more relative to adjacent sub-faults, and if grid size is decreased we smooth the solution more spatially so the inversion is less dependent on discretization. This balances the perturbations of model parameters relative to data fit. Many smoothing approaches were tested, and as for all finitesource inversions, smoothing has significant effect. Our preferred model is representative of the solutions we found to be stable.

\section{Discussion and Conclusions}

[10] Our preferred model (Figure 2) has a seismic moment distribution near the hypocenter generally consistent with a previous combined inversion of teleseismic body waves, surface waves, and low-sample rate (30 s) GPS data for the Tohoku event [Ammon et al., 2011], although the mapping to slip using variable source rigidity from the PREM layered structure enhances up-dip slip similar to inversions of teleseismic P waves [Lay et al., 2011b]. The area for the main rupture spans $\sim 200 \mathrm{~km}$ along strike and $\sim 200 \mathrm{~km}$ along dip, with a rupture asymmetry to the south. The maximum model slip is $\sim 60 \mathrm{~m}$ near the trench and the seismic moment is $\sim 4.8 \times 10^{22} \mathrm{Nm}\left(\mathrm{M}_{\mathrm{w}}\right.$ 9.1). Excellent matches to the recordings were obtained (Figure 3; all data and synthetics are shown in Figure $\mathrm{S} 1$ in the auxiliary material). ${ }^{1}$ The model also provides very good predictions of ground velocities, so it fully captures the time-varying components (Figure S2). Visualizations of the rupture expansion and slip evolution are shown in Animations S1 and S2.

[11] Many parameters influence finite-source inversions, including the station distribution, fault geometry, signal window, rupture velocity, low-pass filter corner period, parameterization of the sub-fault source time functions, and smoothing design. We explored the influence of all of these parameters, finding that the first order pattern shown in Figure 2 is relatively stable. For example, signal window duration was not found to have much influence as long as windows long enough to capture the complete time-varying displacements were used. This is because the full static offset is realized within the time-varying interval, and adding length to the signals does not diminish the importance of the early portions of the signals (Figure S3). The models are most influenced by choice of rupture velocity and smoothing weight, which we discuss below.

[12] For teleseismic inversions, rupture velocity has particularly strong influence on slip patterns, with severe tradeoff due to intrinsic lack of spatial resolution. Slip near the rupture front where the number of parameters is a maximum tends to be preferred by teleseismic least-squares inversions. For our high-rate GPS inversions, the slip pattern is not as strongly affected by the choice of rupture velocity due to having relatively good spatial resolution (Figures 4 and S4). When choosing an appropriate rupture velocity (not too high

\footnotetext{
${ }^{1}$ Auxiliary materials are available in the HTML. doi:10.1029/ 2011GL048700.
} 

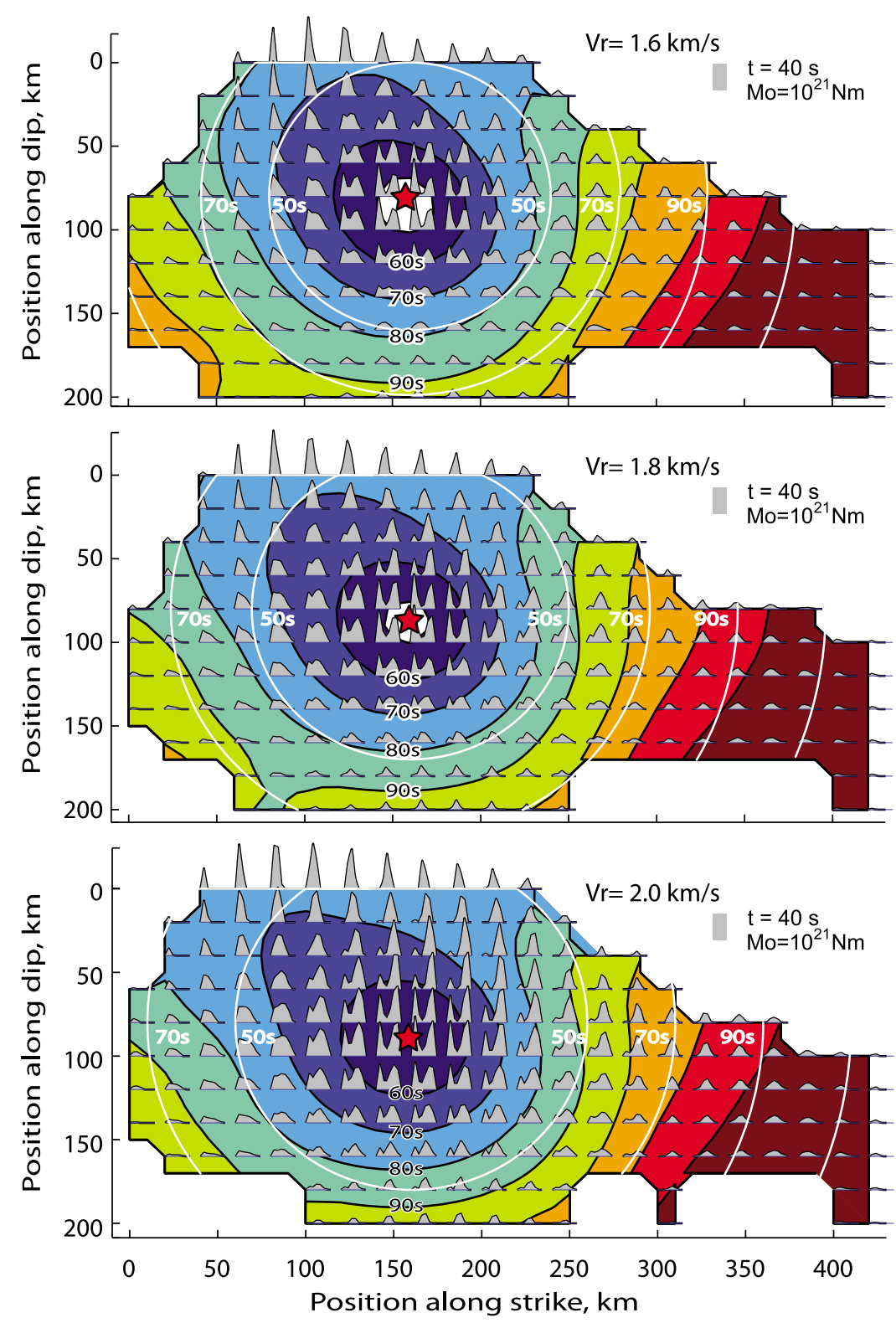

Figure 4. Comparison of sub-fault source function centroid time for inversion results with different rupture velocities of $1.6,1.8$ and $2.0 \mathrm{~km} / \mathrm{s}$. Symbols are the same as in Figure 2.

or too low) with a sub-fault source time function long enough to span the real rupture time, the inversion uses more of the degrees of freedom of each sub-fault source function to fit the data (Figure 4). In our inversion, the centroid time of each sub-fault source function proves quite stable for different choice of rupture velocity ranging from $1.5 \mathrm{~km} / \mathrm{s}$ to $3.0 \mathrm{~km} / \mathrm{s}$ (Figures 2, 4 and S4) and even higher. The up-dip region has a broad region of slip with a moment rate centroid time of around 60-80s (Figure 1), with subfault source time functions being single broad peaks. The down-dip region has a moment rate centroid time of between $70-90 \mathrm{~s}$. There is a southerly lobe with a centroid time of 90-110 s. The central portion of the fault has double peaked sub-fault source time functions, and the large up-dip slip may have driven repeated failure down-dip. The roughness of the sub-fault source functions is dependent on the smoothing, but this may indicate multiple slip fronts as invoked by Ide et al. [2011].
[13] Choosing a suitable smoothing weight usually involves balancing the trade-off between data fit and model roughness. However, our inversions always fit the data with about $97 \%$ variance reduction due to the smooth signals and many finite-fault parameters. On the other hand, the smoothing weight directly influences the maximum slip estimate. Varying the smoothing weight of $\beta_{0}$ between 250 and 750 results in estimates of maximum slip between $80 \mathrm{~m}$ and $58 \mathrm{~m}$ (after scaling by the PREM rigidity structure). Our preferred smoothing weight was selected by requiring the maximum slip amount to be around $\sim 60 \mathrm{~m}$, as observed near the toe of the upper wedge.

[14] Inversions for potency rather than seismic moment were also performed, by multiplying the Green's functions by the depth-varying rigidities for the PREM structure and then inverting for potency. With no smoothing in the inversion, identical slip results are obtained from seismic moment and potency inversions, but modest levels of smoothing are 
required to obtain sensible model behavior. We find basically similar models in slip distribution for potency inversions and seismic moment inversions (scaled to slip) despite the effects of smoothing interacting with the different Green function amplitudes (Figure S5).

[15] The availability of dense, high-rate GPS observations for the great 2011 Tohoku earthquake enables self-consistent, data-balanced seismo-geodetic inversions, and stable rupture models are obtained, with complete ground motions longer than $25 \mathrm{~s}$ being well-modeled using a simple 1D structure. The complete fitting of the combined dynamic and static terms (Figures 2 and S6) provides good spatial and temporal resolution of the faulting process and constraints on the seismic moment, and it will be valuable to have more high-rate GPS data for future events. The inverted slip pattern is stable for moderate changes in model parameters. The slip in the up-dip segment occurs over a large area with source time function durations of $30-40 \mathrm{~s}$. These durations are relatively independent of rupture velocity, but are influenced by smoothing. Slip in the down-dip segments tends to occur in two shorter pulses of about $20 \mathrm{~s}$ duration each, which may be related to stronger short-period radiation observed from the deeper region.

[16] Acknowledgments. This work made use of GMT and SAC software. We thank L. Rivera for providing the normal mode data set. We thank for K. Larson for discussions and helping us to access high-rate GPS data. Our data, generously made available by C. Rocken of GPS Solutions, Inc. originated with efforts by GSI, NGDS, Hitz, GPSS, and VERIPOS. C. J. Ammon and H. Kanamori provided helpful discussions of potency inversion, smoothing, and modeling of high rate GPS recordings using the normal mode approach, which was suggested by C. J. Ammon, and helpful comments on the manuscript. An anonymous reviewer and R. Smalley provided helpful reviews. This work was supported by NSF grants EAR0635570.

[17] The Editor thanks Ali Ozgun Konca and Robert Smalley for their assistance in evaluating this paper.

\section{References}

Ammon, C. J., T. Lay, H. Kanamori, and M. Cleveland (2011), A rupture model of the great 2011 Tohoku earthquake, Earth Planets Space, doi:10.5047/eps.2011.05.015, in press.

Delouis, B., J.-M. Nocquet, and M. Vallée (2010), Slip distribution of the February $27,2010 \mathrm{Mw}=8.8$ Maule earthquake, central Chile, from static and high-rate GPS, InSAR, and broadband teleseismic data, Geophys. Res. Lett., 37, L17305, doi:10.1029/2010GL043899.

Dziewonski, A. M., and D. L. Anderson (1981), Preliminary reference Earth model 1, Phys. Earth Planet. Inter., 25(4), 297-356, doi:10.1016/00319201(81)90046-7.

Fujii, Y., K. Satake, S. Sakai, M. Shinohara, and T. Kanazawa (2011), Tsunami source of the 2011 off the Pacific coast of Tohoku, Japan earthquake, Earth Planets Space, doi:10.5047/eps.2011.06.010, in press.

Hayes, G. (2011), Rapid source characterization of the 03-11-2011 $\mathrm{M}_{\mathrm{W}} 9.0$ Off the Pacific coast of Tohoku earthquake, Earth Planets Space, doi:10.5047/eps.2011.05.012, in press.

Ide, S., A. Baltay, and G. C. Beroza (2011), Shallow dynamic overshoot and energetic deep rupture in the $2011 \mathrm{Mw} 9.0$ Tohoku-oki earthquake, Science, 332, 1426-1429, doi:10.1126/science.1207020.
Iinuma, T., M. Ohzono, Y. Ohta, and S. Miura (2011), Coseismic slip distribution of the 2011 off the Pacific coast of Tohoku earthquake (M9.0) estimated based on GPS data-Was the asperity in Miyagi-oki ruptured?, Earth Planets Space, doi:10.5047/eps.2011.06.013, in press.

Ji, C., K. M. Larson, Y. Tan, K. W. Hudnut, and K. Choi (2004), Slip history of the 2003 San Simeon earthquake constrained by combining 1-Hz GPS, strong motion, and teleseismic data, Geophys. Res. Lett., 31, L17608, doi:10.1029/2004GL020448.

Konca, A. O., S. Leprince, J.-P. Avouac, and D. V. Helmberger (2010), Rupture process of the $1999 \mathrm{M}_{\mathrm{w}} 7.1$ Duzce earthquake from joint analysis of SPOT, GPS, InSAR, strong-motion, and teleseismic data: A supershear rupture with variable rupture velocity, Bull. Seismol. Soc. Am., 100, 267-288, doi:10.1785/0120090072.

Koper, K. D., A. R. Hutko, T. Lay, C. J. Ammon, and H. Kanamori (2011), Frequency-dependent rupture process of the 11 March $2011 M_{\mathrm{W}} 9.0$ Tohoku earthquake: Comparison of short-period $P$ wave backprojection images and broadband seismic rupture models, Earth Planets Space, doi:10.5047/eps.2011.05.026, in press.

Lawson, C. L., and R. J. Hanson (1995), Solving Least Squares Problems, Soc. for Ind. Appl. Math., Philadelphia, Pa.

Lay, T., Y. Yamazaki, C. J. Ammon, K. F. Cheung, and H. Kanamori (2011a), The great 2011 of the Pacific coast of Tohoku $\left(M_{W}\right.$ 9.0) earthquake: Comparison of deep-water tsunami signals with finite-fault rupture model predictions, Earth Planets Space, doi:10.5047/eps.2011. 05.030, in press.

Lay, T., C. J. Ammon, H. Kanamori, L. Xue, and M. J. Kim (2011b), Possible large near-trench slip during the great 2011 Tohoku $\left(\mathrm{M}_{\mathrm{W}} 9.0\right)$ earthquake, Earth Planets Space, doi:10.5047/eps.2011.05.033, in press. Maeda, T., T. Furumura, S. Sakai, and M. Shinohara (2011), Significant tsunami observed at the ocean-bottom pressure gauges at 2011 off the Pacific coast of Tohoku earthquake, Earth Planets Space, doi:10.5047/ eps.2011.06.005, in press.

Miura, S., et al. (2005), Structural characteristics off Miyagi forearc region, the Japan Trench seismogenic zone, deduced from a wide-angle reflection and refraction study, Tectonophysics, 407, 165-188, doi:10.1016/j. tecto.2005.08.001.

Miyazaki, S., et al. (2004), Modeling the rupture process of the 2003 September 25 Tokachi-Oki (Hokkaido) earthquake using $1 \mathrm{~Hz}$ GPS, Geophys. Res. Lett., 31, L21603, doi:10.1029/2004GL021457.

Ozawa, S., T. Nishimura, H. Suito, T. Kobayahi, M. Tobita, and T. Imakiire (2011), Coseismic and postseismic slip of the 2011 magnitude-9 Tohokuoki earthquake, Nature, 475, 373-376, doi:10.1038/nature10227.

Sato, M., et al. (2011), Displacement above the hypocenter of the 2011 Tohoku-oki earthquake, Science, 332, 1395, doi:10.1126/science. 1207401 .

Simons, M., et al. (2011), The 2011 magnitude 9.0 Tohoku-oki earthquake: Mosaicking the megathrust from seconds to centuries, Science, 332, 1421-1425, doi:10.1126/science.1206731.

Wang, D., and J. Mori (2011), Rupture process of the 2011 off the Pacific coast of Tohoku Earthquake ( $M_{\mathrm{w}} 9.0$ ) as imaged with back-projection of teleseismic $P$-waves, Earth Planets Space, doi:10.5047/eps.2011. 05.029, in press.

Yoshida, Y., H. Ueno, D. Muto, and S. Aoki (2011), Source process of the 2011 off the Pacific coast of Tohoku earthquake with the combination of teleseismic and strong motion data, Earth Planets Space, doi:10.5047/ eps.2011.05.011, in press.

Zhao, D., Z. Huang, N. Umino, A. Hasegawa, and H. Kanamori (2011), Structural heterogeneity in the megathrust zone and mechanism of the 2011 Tohoku-oki earthquake (Mw 9.0), Geophys. Res. Lett., doi:10.1029/2011GL048408, in press.

T. Lay and H. Yue, Department of Earth and Planetary Sciences, University of California, 1156 High St., Santa Cruz, CA 95064, USA. (tlay@ucsc.edu) 